\title{
Numerical simulation of dam-burst and reflections, with verification against laboratory data
}

\author{
D. I. H. BARR \&. M. M. DAS
}

\section{Mr K. Sivaloganathan, Lanchester Polytechnic}

The assessment of the validity of any mathematical simulation that uses the $\mathrm{St}$ Venant equations may be considered as consisting of two stages: ensuring that the numerical solution arrived at is a sufficiently accurate solution of the St Venant equations, and verifying whether or not the numerical solution matches the experimental results adequately in a sufficient and representative number of cases.

28. To ensure adequate accuracy of the solutions the difference equations used must be consistent with the St Venant differential equations and be stable, and the grid size used must be sufficiently small. The Authors state that theirs is an explicit scheme but do not mention how the term $x_{k}^{j+1}$ is evaluated. One assumes they have evaluated it using a function of the dependent variables at the grid point $(k, j)$ possibly a relationship of the form $\left(x_{k}^{j+1}-x_{k}^{j}\right) / t=m_{k}^{j}$ where $m_{k}^{j}$ is a function of one or both of the variables $y_{k}^{j}$ and $V_{k}^{j}$. The Authors have used the same symbols to denote the dependent variables at the fixed grid points on the lower time level and at the first calculated points on the higher time level. If, for clarity, $y$ and $V$ are used only to denote the depth and velocity respectively at the fixed grid points (assuming $x_{k}^{j}<x_{k}^{j+1}<x_{k+1}^{j}$ from Fig. 2), equations (11) and (12) reduce to

$$
\begin{aligned}
y_{k}^{j+1}= & (1-M)\left[y_{k-1}^{j}-\frac{\Delta t}{2 \Delta x} y_{k-1}^{j}\left(V_{k}^{j}-V_{k-2}^{j}\right)-\frac{\Delta t}{2 \Delta x}\left(V_{k-1}^{j}-m_{k-1}^{j}\right)\left(y_{k}^{j}-y_{k-2}^{j}\right)\right] \\
& +M\left[y_{k}^{j}-\frac{\Delta t}{2 \Delta x} y_{k}^{j}\left(V_{k+1}^{j}-V_{k-1}^{j}\right)-\frac{\Delta t}{2 \Delta x}\left(V_{k}^{j}-m_{k}^{j}\right)\left(y_{k+1}^{j}-y_{k-1}^{j}\right)\right] \\
V_{k}^{j+1}= & (1-M)\left[V_{k-1}^{j}-\frac{\Delta t}{2 \Delta x}\left(V_{k-1}^{j}-m_{k-1}^{j}\right)\left(V_{k}^{j}-V_{k-2}^{j}\right)\right. \\
& -g \frac{\Delta t}{\Delta x}\left(y_{k}^{j}-y_{k-2}^{j}\right)+g \Delta t\left(S_{0}-S_{f}\right)_{k-1}^{j} \mid \\
& +M\left\lfloor V_{k}^{j}-\frac{\Delta t}{2 \Delta x}\left(V_{k}^{j}-m_{k}^{j}\right)\left(V_{k+1}^{j}-V_{k-1}^{j}\right)\right. \\
& \left.-g \frac{\Delta t}{\Delta x}\left(y_{k+1}^{j}-y_{k-1}^{j}\right)+g \Delta t\left(S_{0}-S_{f}\right){ }_{k}^{j}\right]
\end{aligned}
$$

Paper published: Proc. Instn Civ. Engrs, Part 2, 1980, 69, June, 359-373. 
where

$$
M=\frac{\Delta x-m_{k-1}^{j} \Delta t}{\Delta x+\left(m_{k}^{j}-m_{k-1}^{j}\right) \Delta t}
$$

29. Using Taylor expansions as appropriate, it can be shown that equations (35) and (36) tend to the St Venant differential equations in the limit. The difference scheme used is thus consistent with the St Venant differential equations. However, a stability analysis on equations (35) and (36) using the Von Neumann technique gives, for the amplification factor, a complicated expression containing dependent variables from both the grid points $(k-1, j)$ and $(k, j)$. It does not seem easy to draw general conclusions from this expression. However, in the limiting case when $m_{k}^{j}=0$ (i.e. when the grid used is a fixed grid) the Authors' difference scheme reduces to the often quoted unstable scheme. ${ }^{21-23}$ Fortunately, stability analyses conducted with the friction term included show that the possibility of stable computation exists, ${ }^{21}$ but $\Delta t$ has to satisfy both an upper limit determined by the Courant condition and a lower limit determined by the friction effects and it may not always be possible to satisfy these conditions at all grid points on a time level with a single value of $\Delta t$. There are examples of the successful use of the 'unstable scheme' but in general it is prudent to a void the use of schemes that analyses show are likely to be unstable. Have the Authors made an assessment of their numerical solutions and, if so, how do the assessed errors in the solutions compare with the likely experimental errors?

30. The Authors imply that in the case of laboratory phenomena, the Colebrook-White formula is the more appropriate formula to use for the evaluation of the friction slope for unsteady channel flow. Although the Authors' computed results match the experimental results adequately, they are not by themselves sufficient to establish the aforementioned point of view. It is necessary to compare them with computed results using the Manning (or Chezy) formula with appropriate values for the relevant constants, to assess the validity of the said point of view. I feel that the Manning (or Chezy) formula will serve the purpose equally well with an appropriate choice of the values of the relevant constants.

\section{Professor Barr and Dr Das}

In the real sense, the term $x_{k}^{j+1}$ is unknown because this is a term to be calculated in the next time step. Therefore, in explicit equations such as equations (11) and (12), the evaluation of such a term in the right-hand side may present a problem. Our experience shows that the computation of dam-break wave profiles in a dry bed is a complex problem. This is due first to the initial discontinuity of $y$ at $z=0$ when $t=0$, second to the moving calculation boundaries, and third to the singularity at the front (in dry bed) when $y=0$. Because the actual procedure for computation of $x_{k}^{j+1}$ along the lines suggested by Mr Sivaloganathan may further aggravate the complexity of computation, for simplicity we used an approximate method. The term $x_{k}^{j+1}$ denotes the locations on the first calculated points (see Fig. 2) reached by the fluid particles in a small time $\Delta t$ from the known variables at $x_{k}^{j}$ locations. Thus the term $\left(x_{k}^{j+1}-x_{k}^{j}\right)$ in equations $(11)$ and (12) represents the distances covered by the fluid particles from their known positions of $x_{k}^{j}$ with velocity $V i$ in the small time $\Delta t$. Hence, for simplicity, a very closely approximating value of $\left(x_{k}^{j+1}-x_{k}^{j}\right)$ is taken to be $(V k \Delta t)$.

32. From our experience, and from our review of the literature on flood propagation due to dam failure, the explicit method of solution has proved to be suitable $^{24-28}$ and does not appear to be inherently less stable than the implicit 
method at the small integration time step, selected by the usual Courant criterion, with small grid sizes. Moreover, computer run time is much less although storage capacity has to be greater. On Mr Sivaloganathan's remark that our explicit method in the limiting case reduces to the often quoted unstable scheme, ${ }^{21-23}$ it should be borne in mind that these conclusions ${ }^{23}$ were based primarily on stability rather than accuracy or efficiency requirements. The explicit method provides the most direct and the fastest solution, provided care is taken, if the dependent variables are changing rapidly, that small grid sizes are adopted to prevent poor representation of the non-linear terms in the equation. If the dependent variables are changing slowly, grid size may be increased to take the advantage of longer time step. Although the implicit method is inherently stable, provided the Courant condition is not violated, it is found that in the dam-break problem there are considerable difficulties ${ }^{29}$ owing to the complexity of the situation.

33. There is often confusion between the nature of the Chezy formula, the Manning formula, the Colebrook-White function and now a generalized Colebrook-White function, or even a generalized Poiseuille-Colebrook-White function ${ }^{30}$ The Chezy equation is a particular formulation of friction factor taking into account Chezy's recognition of the hydraulic mean depth as unifying variable as between different cross-sections of flow. The Manning equation also does this but, as has been shown on many occasions, is a rough turbulent law which can be arranged to correspond quite closely to part of the range delineated by the logarithmic rough turbulent law. Then there are the possibilities of delineating values of friction factor as a result of the influences of smoothness and noncommercial roughness. A simple evaluation of a friction factor is sufficient if it happens to be appropriate for the situation of application, but the point of resistance formulae is that they cover different situations. Our experiments did this and, were a new series to be mounted, would include small-scale experiments where flow would clearly run into the laminar region. Thus, we believe that, for progress, there must be capacity for dealing with all flow and roughness situations. We are alarmed at the possibility of the occurrence of decalibration by the process of adjusting coefficients of mathematical models, which can deal only with rough turbulent flow, using laboratory data obtained under smooth turbulent or transition turbulent conditions.

\section{References}

21. Ligget J. A. and Cunge J. A. Numerical methods of solution of unsteady flow equations. In Unsteady flow in open channels, K. Mahmood and V. Yevjevich (eds). Water Resources Publications, Fort Collins, 1975, 111-114.

22. YevJevich V. and BARNes A. B. Flood routing through storm drains, Part 4. Colorado State University, 1970, Hydrology paper 46, 6-7.

23. Liggett J. A. and WoOlhiser D. A. Difference solutions of the shallow water equations. J. Engng Mech. Div. Am. Soc. Civ. Engrs, 1967, 93, EM 2, Apr., 39-71.

24. MARVAUd $P$. Etude sur machine à calcular des mouvements non permanents dan les rivières et canaux. Centre de Recherches et d'Essais de Chatou, Départment Laboratoire National d'Hydraulique, 1966.

25. MusKatirovic D. The study of hydraulic effects of instantaneous and total breaking of Glaznja and Lipkovo Dams. J. Cerni Institute, 1971.

26. Chen C.-L. and ARMBruster J. T. Dambreak wave model: formulation and verification. J. Hydraul. Div. Am. Soc. Civ. Engrs, 1980, 106, May, 747-767.

27. Balloffet A. et al. Dam collapse wave in a river. J. Hydraul. Div. Am. Soc. Civ. Engrs, 1974, 100, May, 645-665. 
28. MusKatirovic D. Some experiences relevant to numerical calculations of hydraulic consequences of dam failure. Proc. 15th Congr. Int. Assn Hydraul. Res., Istanbul, $1973,5,9-15$.

29. Muskatirovic D. and Parezanovic. Hydraulic calculation of dam failure effects by method of characteristics by digital computer for the case of natural watercourses. Proc. 4th Congr. Yugoslav Soc. Hydraul. Res., Sarajevo, 1966.

30. Barr D. I. H. The transition from laminar to turbulent flow. Proc. Instn Civ. Engrs, Part 2, 1980, 69, June, 555-562. 